\section{Quality of life in black African patients with keloid scars}

Komenan Kassi, Kanga Kouame, Alexandre Kouassi, Ange Allou, Isidore Kouassi, Sarah Kourouma, Elidje Ecra, Abdoulaye Sangare

Department of dermatology and venerology, Training and research units of medical sciences, University of Felix Houphouet-Boigny of Abidjan, Côte d'Ivoire

\begin{abstract}
A keloid scar is a benign skin tumor and we aimed to assess the Quality of Life (QoL) of black Africans with keloid scars based on the Dermatology Life Quality Index (DLQI). We conducted a cross-sectional descriptive study in the department of dermatology of the teaching hospital of Treichville in Ivory Coast. We recruited 132 patients with keloid and 3612 dermatoses without keloid: The prevalence was $3.50 \%$ (132/3753). We included 120 patients aged from 16 to 63 years old, the sex ratio was $0.46(38 / 82)$ and the mean age was 34.20 years. Keloid scars were mostly secondary to skin trauma in $30.00 \%$ and infection in $21.67 \%$. The commonest site was the ear in $29.17 \%$. We reported Keloid with pain in $53.33 \%$ and pruritus in $95.00 \%$. We observed psychological impact in $65.83 \%$. The DLQI scores were moderate and high in $61.66 \%$. QoL was impacted significantly when keloid was associated with pain $(\mathrm{p}=0.046)$, pruritus $(\mathrm{p}=0.81)$ and functional disorders $(\mathrm{p}=0.29)$. The DLQI score could be a valuable tool to assess QoL in black African patients with keloid, for better treatment option.
\end{abstract}

\section{Introduction}

A keloid scar is a hyper-proliferation of fibroblasts characterized by over production and abnormal deposition of collagen. It can occur spontaneously or secondary to skin trauma or infections. ${ }^{1}$ A keloid scar is more likely in an individual with dark, pigmented skin. This excessive scar formation can extend beyond the original boundaries of the initial wound. ${ }^{2}$ Usually, it is a hyper-pigmented, erythematous, painful and often pruritic, with irregular borders and poor cosmetic effect. ${ }^{1,3,4}$ The exact pathology remains incompletely understood and complex, and involves genetic and environmental factors. ${ }^{1}$ A keloid scar can lead to esthe- tic, physical, and psychological impacts in affected patients.

Treatment of a keloid scar is complex, difficult and frequently associated with recurrence. ${ }^{5}$ Several treatment options are available, all of which are aimed to controlling to different degrees physical symptoms. However, treatments do not take account of the feelings, ability to fulfill daily tasks, or quality of life (QoL) of a patient with a disfiguring symptomatic keloid scar. ${ }^{2}$

We aimed to assess the impact of keloid scars on the QoL of black African patients. We did so by focusing on the perceptions and psychological impact of having these disfiguring benign tumors.

\section{Materials and Methods}

\section{Type of study and duration}

This was a cross-sectional descriptive study of all cases of keloid scars diagnosed in the department of dermatology of the teaching hospital of Treichville (Abidjan, Côte d'Ivoire) from July $1^{\text {st }}$ to December $31^{\text {st }} 2017$.

\section{Patients}

We recruited patients of both sexes and ages who consulted for keloid scars in the department of dermatology at a teaching hospital in Treichville during the study period.

\section{Inclusion criteria}

The inclusion criteria were patients aged of 16 years old and over who consulted for one or multiple keloid scars evolving over 1 year and who gave their oral or written informed consent to participate in the study.

\section{None inclusion criteria}

The none inclusion criteria were patients with an allergy or adverse reactions to certain drugs (e.g., lidocaine, corticosteroids); chronic dermatoses (e.g., psoriasis); aged $<16$ years presenting with a keloid scar; hypertrophic scars and patients with other dermatoses.

\section{Collection and analyses of data}

A survey comprising 37 questions related to demographics, clinical features, and impact on QoL was completed. Data were recorded on paper.

Demographic data included age, sex, ethnic group, marital status, education level, and employment type, clinical features focused on the history/length/location of keloid scars, history of previous treatment, length of time since the keloid scar devel-
Correspondence: Komenan Kassi, Department of dermatology and venerology, Training and research units of medical sciences, University of Felix Houphouet-Boigny of Abidjan, 01 BP V 166 Abidjan, Côte d'Ivoire

Tel.: +22507047601

E-mail: siskakomlo@yahoo.fr

Key words: Keloid; Black African; QoL; DLQI.

Acknowledgments: we would like to thank all health practitioners from the dermatology department and venerology of the teaching hospital of Treichville of Abidjan.

Conflict of interest: the authors declare no potential conflict of interests.

Ethical considerations: Oral and written informed and consent for publication of information relating to patients in a medical journal was obtained from patients.

Received for publication: 18 September 2019. Accepted for publication: 24 May 2020.

This work is licensed under a Creative Commons Attribution-NonCommercial 4.0 International License (CC BY-NC 4.0).

${ }^{\circ}$ Copyright: the Author(s), 2020

Licensee PAGEPress, Italy

Dermatology Reports 2020; 12:8312

doi:10.4081/dr.2020.8312

oped, pain, and pruritus were collected. The diagnosis was made on clinical presentation based on the scars having the following features: thick erythematous cutaneous growth, borders beyond the original wound, and no spontaneous regression within one year. The impact on QoL was based on the Dermatology Life Quality Index (DLQI) questionnaire (which is an easy to use and practical assessment tool). The DLQI questionnaire comprises 10 questions. It measures the impact in six domains: symptoms/feelings, daily activities, leisure, work/school, personal relationship and treatment. Each question is scored on a four-point Likert scale: 0-1 (no impact); 1-5 (small impact); 5-10 (moderate impact); 10 20 (large impact); 20-30 (very large impact). The DLQI has been validated for 32 skin conditions, including keloid scars. ${ }^{6}$

\section{Statistical analyses}

Data were analyzed by Epi Info ${ }^{\mathrm{TM}}$ v3.5.1 (Centers for Disease Control, Atlanta, GA, USA). Differences between proportions were compared using the Chi square test. 


\section{Results}

\section{Epidemiology}

The prevalence of keloid scars during the study period was $3.5 \%$ from all dermatoses documented (132/3753 cases). The 3612 non-keloids patients were diagnosed for other dermatoses without keloid scars. Only 120 patients aged of 16 years old and over were included in our study.

\section{Demographics}

The cohort the 120 patients were mostly females in $68.33 \%$ versus $31.67 \%$ of males with a sex-ratio of 0.46 . The mean age of patients was 34.20 (from 16 to 63 ) years. Patients had mostly senior high school (48.33\%) and junior high-school (35.83\%) education. Civil servants $(37.50 \%)$ and students $(22.50 \%)$ were the most prevalent professional categories (Table 1).

\section{Clinical features}

Family and personal histories of keloid scars were reported from patients in $38.8 \%$ of cases. Keloid scars were secondary to skin lesions in $88.33 \%$ of cases. Frequent causes were skin trauma ( $30.00 \%$ of cases), infection $(21.67 \%)$, piercing $(18.33 \%)$ and surgery $(14.17 \%)$. The common sites were ears $(29.17 \%$ of cases), face (18.32\%), and trunk $(19.17 \%)$. Keloid scars were associated with pain in $53.33 \%$ of cases, pruritus in $95.00 \%$ and suppuration/ulceration in $19.17 \%$. Functional and psychological (with anxiety report by patient) disorders were noted in $33.33 \%$ and $65.83 \%$ of cases, respectively (Table 2).

\section{DLQI score and QoL}

The DLQI score was "low" in $38.33 \%$ "moderate" in $45.00 \%$ of cases and "high" in $16.66 \%$ of patients.

We observed a relationship between the DLQI score and age, sex, pain, pruritus, suppuration/ulceration and functional disorders. QoL was impacted most between 16 years and 35 years of age. QoL was affected more in females than in males. Keloid scars associated with pain, pruritus and functional disorder had a statistically significant impact on QoL (Table 3).

\section{Discussion}

Despite research focusing on understanding keloid scars, their treatment is challenging. The factors associated with a high DLQI score for keloid scars were pain and itching, as reported by Goldstein and colleagues. ${ }^{7}$ Also, itchy and painful keloids have been associated with the greatest impairment of health-related QoL, whereas cosmetic factors such as color, thickness and irregularity of scars are less related..$^{8,9} \mathrm{~A}$ cross-sectional study conducted by Casemir and colleagues involving 106 patients with keloid scars but without other skin diseases showed that $48 \%$ of cases had severe emotional symptoms, and that the key determinants were pain and itching. Lemonas and colleagues found pain and pruritus to be common physical symptoms that impact the QoL of people with keloid scars ${ }^{6}$. Carr and co-workers showed that the greatest effect on QoL was the psychological distress of living with disfiguring keloid scars. ${ }^{10}$

The DLQI is a sensitive tool to detect and evaluate the impact of keloid scars on QoL. ${ }^{11}$ Morales-Sanchez et al. reported that the dimension that contributed most to the total DLQI score was symptoms and feel-

Table 1. Demographic aspects of the study cohort.

\begin{tabular}{lcc} 
Parameter & Number $(\mathrm{n}=\mathbf{1 2 0})$ & Percentage (\%) \\
Sex & & \\
$\quad$ Female & 82 & 68.33 \\
$\quad$ Male & 38 & 31.67 \\
Age (years) & & \\
16-36 & 70 & 58.33 \\
$36-56$ & 40 & 33.33 \\
$56-63$ & 10 & 08.34 \\
\hline Level of education & & \\
Junior high school & 43 & 35.83 \\
Senior High school & 58 & 48.33 \\
$\quad$ Illiterate & 19 & 15.84 \\
Employment & & \\
Civil servant & 45 & 37.50 \\
Student & 27 & 22.50 \\
Farmer or laborer & 33 & 27.50 \\
Home worker & 6 & 5.00 \\
Retired & 4 & 3.33 \\
Military & 3 & 2.50 \\
Unemployed & 2 & 1.67 \\
\hline
\end{tabular}

Table 2. Clinical features of the study cohort.

\begin{tabular}{lcc} 
& Number $(\mathrm{n}=\mathbf{1 2 0})$ & Percentage (\%) \\
Personal and family histories & & 37.50 \\
$\quad$ Yes & 45 & 62.50 \\
Of Keloid scars & 75 & 11.67 \\
$\quad$ No & 14 & 88.33 \\
Spontaneous keloid scars & 106 & 18.33 \\
Cause of secondary keloid scars & 22 & 4.17 \\
$\quad$ Piercing & 5 & 14.17 \\
Hair shaving & 17 & 21.67 \\
Surgery & 26 & 30.00 \\
Skin trauma and burning & 36 & \\
& & 29.17 \\
Site & 35 & 19.17 \\
$\quad$ Ear & 23 & 14.17 \\
Trunk & 17 & 18.32 \\
Limbs & 22 & 10.00 \\
Face & 12 & 5.00 \\
Pelvis and vulva & 6 & 4.17 \\
Shoulder & 5 & \\
Abdomen & & 53.33 \\
Symptoms & 64 & 95.00 \\
Pain & 114 & 19.17 \\
Pruritus & 22 & 33.33 \\
Suppuration/ulceration & & 65.83 \\
\hline Disorders & 40 & \\
Functional & 79 & \\
Psychological & & \\
\hline
\end{tabular}


ings. Their study revealed that the impact on QoL was associated with self-reporting of depressive symptoms but it did not allow them to attribute a causal relationship. ${ }^{12}$ In addition, patients with keloid scars that are covered by clothing appear to have a greater psychological impact, and they adopt concealment strategies or attitudes to cope ${ }^{6}$. Scholars ${ }^{13}$ have shown that the DLQI as a tool to measure QoL in patients with keloid scars can be: i) used to measure clinical outcome; ii) combined with a validated psychometric measure (Derriford Appearance Scale-24) and used as a psychological screening tool.

Some studies ${ }^{13}$ have revealed that psychological distress in patients with keloid scars is related directly to patient-perceived scar severity but is unrelated to clinicianrated scar severity. Patients who perceive the scar to be severe anticipate greater social difficulties, thereby causing psychological distress. ${ }^{13}$

Bijlard and colleagues reported that pain and itching were consistently and strongly associated with health-related QoL. ${ }^{5}$ Robles and colleagues reported that keloid scars are the most challenging skin diseases to treat successfully, and are associated with significant psychological impact for patients. ${ }^{3}$ Nevertheless, most patients desire definitive and efficacious treatment of keloid scars. The DLQI could add valuable insights into the psychological and functional impairment of QoL. ${ }^{14}$

The small number of our study population represented one of the limitations of this study. Although, we reported statistically significant relationship between DLQI scores and QoL impact in keloid scar patients associated with pain, pruritus, suppuration, age, sex and functional disorders, we cannot firmly conclude.

In Africa, the treatment needs of affected patients are not met ${ }^{15}$ because of the high financial cost related to the care of keloid scars. However, understanding the evolution of keloid scar characteristics and QoL score over the course of keloid treatment allows dermatologists to provide the correct information to patients on therapeutic effects and side effects. In some cases, the DLQI could be useful to manage patients' expectations and to setup realistic treatment goals ${ }^{16}$ that should take account all aspects of patients' needs. ${ }^{17}$ Therefore, dermatologists should take into account signs, symptoms, individual needs, QoL and psychological wellbeing to direct curative treatment options. ${ }^{18}$ Contemporaneous international clinical recommendations on scar management must also be considered. ${ }^{19}$

Table 3. DLQI Impact on quality of life(QoL).

\begin{tabular}{|c|c|c|c|c|}
\hline \multirow[t]{2}{*}{ Impact } & \multicolumn{4}{|c|}{ P-value } \\
\hline & & No & Yes & \\
\hline $\begin{array}{l}\text { Functional } \\
\text { Disorders }\end{array}$ & $\begin{array}{l}\text { Yes } \\
\text { No }\end{array}$ & $\begin{array}{c}0 \\
0 \% \\
4 \\
(5.00 \%)\end{array}$ & $\begin{array}{c}40 \\
-100 \% \\
76 \\
(95.00 \%)\end{array}$ & $\mathrm{P}=0.29$ \\
\hline $\begin{array}{l}\text { Suppuration/ } \\
\text { ulceration }\end{array}$ & $\begin{array}{l}\text { Yes } \\
\text { No }\end{array}$ & $\begin{array}{c}0 \\
0 \% \\
4 \\
(4.10 \%)\end{array}$ & $\begin{array}{c}22 \\
-100 \% \\
94 \\
(95.90 \%)\end{array}$ & $P=0.43$ \\
\hline Pruritus & $\begin{array}{l}\text { Yes } \\
\text { No }\end{array}$ & $\begin{array}{c}4 \\
(3.50 \%) \\
0 \\
(0.00 \%)\end{array}$ & $\begin{array}{c}110 \\
(96.50 \%) \\
6 \\
-100 \%\end{array}$ & $\mathrm{P}=0.81$ \\
\hline Pain & $\begin{array}{l}\text { Yes } \\
\text { No }\end{array}$ & $\begin{array}{c}0 \\
(0.00 \%) \\
4 \\
(7.00 \%)\end{array}$ & $\begin{array}{c}64 \\
-100 \% \\
52 \\
(93.00 \%)\end{array}$ & $P=0.046$ \\
\hline sex & $\begin{array}{c}\text { Female } \\
\text { Male }\end{array}$ & $\begin{array}{c}2 \\
(2.40 \%) \\
2 \\
(5.30 \%)\end{array}$ & $\begin{array}{c}80 \\
(97.60 \%) \\
36 \\
(94.70 \%)\end{array}$ & $P=0.39$ \\
\hline Age & $\begin{array}{c}16-35 \text { ans } \\
36-55 \text { ans } \\
\geq 56 \text { ans }\end{array}$ & $\begin{array}{c}3 \\
(4.30 \%) \\
1 \\
(2.50 \%) \\
0 \\
0 \%\end{array}$ & $\begin{array}{c}67 \\
(95.70 \%) \\
39 \\
(97.50 \%) \\
10 \\
-100 \%\end{array}$ & $P=0.73$ \\
\hline $\begin{array}{l}\text { Psychological } \\
\text { Impact }\end{array}$ & $\begin{array}{l}\text { Yes } \\
\text { No }\end{array}$ & $\begin{array}{c}1 \\
(1.15 \%) \\
3 \\
(09.10 \%)\end{array}$ & $\begin{array}{c}86 \\
(98.85 \%) \\
30 \\
(90.90 \%)\end{array}$ & $\mathrm{P}=0.20$ \\
\hline
\end{tabular}

\section{Conclusions}

Keloid scars are frequent in black African patients. Their care remains complex and combine more than 2 treatment options, due to frequent recurrences. Therefore, patients with keloid scars require accurate assessment of their QoL using DLQI scores for appropriate treatment strategy that includes physical and psychological aspects.

\section{References}

1. Hunasgi S, Koneru A, Vinishra M, et al. Keloid: a case report and review of pathophysiology and differences between keloid and hypertrophic scars. J Oral Maxillofac Pathol 2013;17:11620.

2. Kelly P. Update on the management of keloids. Semin Cutan Med Surg 2009; 28:72-8.

3. Robles DT, Berg D. Abnormal wound healing: keloids: Clin Dermatol 2007;25:26-32.

4. Gauglitz GG, Korting HC, Pavicic T, et al. Hypertrophic scarring and keloids: pathomechanisms and current and emerging treatment strategies. Mol Med 2011;17:113-25.

5. Bijlard E, Konwenberg C, Timman R, et al. Burden of keloid disease: a crosssectional health-related quality of life assessment. Acta Derma Venerol 2017;97:225-9.

6. Lemonas P, Ahmad I, Falvey H, et al. Keloid scars: the hidden burden of disease. Pigment Disord 2015; 2:12-31.

7. Furtado F, Hochman B, Ferrara SF, et al. What factors affect the quality of life of patients with keloids? Revista Da Associacos Medica Brasileira 2009;57: 700-4.

8. Konwenberg C, Bijlard E, Timman R, et al. Emotional quality of life is severely affected by keloid diseases: pain and itch are the main determinants of burden. Plast Reconstr Surg 2015;136:1501.

9. Brown BC, McKenna SP, Sickdih K, et al. The hidden cost of skin scars: quality of life after skin scaring. J Plast Reconstr Aesthet Surg 2008;61:104958.

10. Carr T, Moss T, Harris D. The DAS24: a short form of the Derriford appear- 
ance scale DAS54 to measure individual responses to learning with problem of appearance. Br J Health Psychol 2005;10:285-95.

11. Balci DD, Inandi T, Dogramaci CA, et al. DLQI scores in patients with

keloids and hypertrophic scars: a prospective case control study. J Dtsch Dermatol Ges 2009; 7:688-92.

12. Morales-Sanchez MA, FloresRuvalcaba CN, Peralta-Pedrero ML et al. Quality of life in adults with keloid scars. Cir Cir 2018;86:321-6

13. Brown BC, Moss TP, McGrouther DA, et al. Skin scar preconceptions must be challenged: importance of self-perception in skin scarring. J Plast Reconstr Aesthet Surg 2010;63:1022-9.

14. Reinholz M, Poetshke J, Schwaiger H, et al. The Dermatology Life Quality Index as a mean to assess life quality in patients with different scar types. JEADV 2015;29:2112-9.

15. Olaitan PB. Keloids: assessment of psychosocial-impacts on subjects in black African population. Indian J Dermatol Venerol Leprol 2009;75:368-72.

16. Poetschke J, Reinholz M, Schwaiger H, et al. DLQI and POSAS scores in keloid patients. Facial Plast Surg 2016;37:289-
95.

17. Gauglitz GG. Management of keloids and hypertrophic scars: current and

emerging options. Clin Cosmet Investig Dermatol 2013;6:103-14.

18. Ud-Din S, Bayat A. Strategic management of keloid disease in ethnic skin: a structure approach supported by the emerging literature. Brit J Dermatol 2013;169:71-81.

19. Gold MH, Berman B, Clementoni MT, et al. Updated international clinical recommendations on scar management: part 1-evaluating the evidence. Dermatol Surg 2014;40:817-24. 